\title{
Commentary
}

Hillel Schmid*

\section{Reflections on the Relationship between the Government and Civil Society Organizations during the Covid-19 Pandemic: The Israeli Case}

https://doi.org/10.1515/npf-2021-0003

Received October 25, 2020; accepted January 18, 2021

Abstract: The paper analyzes the relations between the government and Civil Society Organizations (CSOs) during the COVID-19 pandemic in Israel. The paper presents the inconsistent policy of the government, which has been influenced by various interest groups and the very limited financial support allocated to CSOs during the health, economic and social crisis. The paper describes the government's alienated attitude toward the CSOs as well as the reasons for that behavior. Special attention is devoted to the government's misunderstanding of the mission and roles of CSOs in modern society, especially at times of crisis and national disasters. The paper also analyzes the organizational and strategic behavior of CSOs toward the government, which has also contributed to the alienated attitude of the government toward them. I argue that relations between CSOs and the government should be based on more trust, mutuality, and understanding on the part of both actors in order to change power-dependence relations, and that there is a need to establish more cross-sectoral partnerships for the benefit of citizens.

Keywords: COVID-19 pandemic, government, civil society organizations, alienation, financial support, collaboration

\section{Introduction}

Crises test the strength and sturdiness of relationships between individuals, communities, and organizations. Crises also provide an opportunity to rethink

\footnotetext{
*Corresponding author: Hillel Schmid, Social Work and Social Welfare, Hebrew University, Jerusalem, Israel, E-mail: hillel.schmid@gmail.com
} 
what has existed as well as a time for renewal, implementation of changes, and adjustments to a changing reality.

The premise of this commentary is that the Israeli government's ambivalent attitude towards CSOs did not begin during the outbreak of this crisis, but rather has much deeper roots. This approach results from relationships that developed between government and organizations in the years leading up to the current crisis. I aim in this commentary to trace the factors underlying governmental policies towards CSOs during the crisis. These policies have been characterized by a lack of support for the work of these organizations, often indeed threatening their very survival.

The covid-19 crisis is different from any crisis previously known in that it global in scope and scale. This crisis has particularly stricken such underprivileged populations as individuals with limited education and training, nonunionized workers from low-tech industries, young adults, and older persons. It has harmed women who were placed on unpaid leave or were fired, especially young women and those without academic education. It has impacted members of minorities, low-income households, and self-employed owners of very small businesses. These are in large part the people who constitute most of the recipients of the social services provided by civil society organizations.

The Israeli government behaved as bewildered and confused during the first months of the pandemic. The confusion and inconsistency that characterized the government's behavior continued throughout the "second wave," and then the "third" of the pandemic.

Government policy between March and December 2020 was characterized by the implementation of unprecedented restrictions on the public. With the goal of stopping the spread of the virus, the government violated human rights including freedom of movement, the right to privacy, freedom of association with others, freedom of trade, culture, sports, and other areas. This was accomplished through the enactment of emergency laws - some without any parliamentary supervision. In the framework of the declared emergency, the government shut down the court system almost completely, deployed army forces, and instructed the Shabak (Israel Security Agency) to monitor all residents in order to locate those who came in contact with anyone who tested positive for covid-19. Lack of transparency characterized government decisions, including a decision not to publish normal protocols for the next 30 years. The government's management of the crisis was severely impacted by submission to political pressures as control of the pandemic was lost.

As a result, the government faced a deepening health, economic, and social crisis. The shutdown of trade, industry, and many other market branches led to a significant increase in the rate of unemployment - to $20 \%$ as compared with $3.6 \%$ 
before the outbreak of the crisis - and many businesses folded. The government was faced with pressure and demand to provide grants to help businesses and citizens keep their head above water. These also included demands from CSOs experiencing severe economic disruption.

This commentary begins with a brief description of the consequences of the crisis on organizations which provide social services and the results of their demands for economic support from the government. Next, the causes of the government's ambivalent attitude towards the CSOs and their role in shaping this relationship is presented. The commentary concludes with thoughts about the future of relations between the government and CSOs as well as implications of government policies for the CSOs during crises and emergency situations.

\section{The Implications of the Health and Economic Crisis for Civil Society Organizations}

As a result of the pandemic, many, if not most, CSOs have found themselves in severe financial crisis. A survey conducted by the umbrella organization "Civil Leadership" (March 2020) examined 164 organizations. The results show that in $70 \%$ of the organizations the number of paid employees was reduced and $55 \%$ of the employees were placed on leave without pay or were fired. Sixty-six percent of the large CSOs and 54\% of the small ones reported financial damages. Eighty-five percent of the large and $86 \%$ of the small organizations reported damage to and reduction of services, while in $28 \%$ of the large organizations and $38 \%$ of the small ones services completely halted. Eighty-nine percent of the large CSOs reported reduced income from government and self-generated revenues and $61 \%$ reported reduced income from donations. Many CSOs were unable to pay rent for the use of their facilities and could not acquire equipment for protection from the coronavirus.

As for volunteer activity in CSOs, the percentage of volunteers declined to $8.1 \%$ between April and September 2020, whereas the percentage decline of volunteers in the general population was 31.4\% (Katz and Feit 2020). Findings also indicated that there was an $18 \%$ decrease in contributions of households to CSOs, $20 \%$ decrease in the number of contributors, and 12\% decrease in the amounts of contributions as compared to 2019.

Regarding the entire population, studies show that the percentage of volunteering among Israeli citizens over age 18 during the crisis was 20.3\% almost equal to the percentage of volunteers among that population in normal times $(23.3 \%$, Almog-Bar and Bar 2020). 
CSOs turned to the government for financial assistance, but their demands were only partially met. Israeli philanthropy was mobilized for the benefit of the organizations, but even in this case the worth of the grants was quite limited. The government had announced another financial plan that would rescue the CSOs from economic hardship, but several months since the announcement, the government is having difficulty determining the criteria for receipt of this support.

The current crisis has put the relationships between the government and the CSOs to the test and raises many important questions: Why does the government not treat these organizations supportively, as might be expected from partners who have traveled a long way together? Why, in such difficult times, is the government alienated from the CSOs which are meant to serve as the government's delegates in the provision of social services?

A literature review of government-CSOs relations reveals that many researchers have addressed questions related to the nature of the relationship, developed various theories, analyzed the power-dependency relationships, examined the policies and the strategies of action of both sides, proposed different models to clarify the boundaries between the organizations, and devoted thought and research to issues of accountability and transparency (Almog-Bar 2016; Gronbjerg and Salamon 2012; Najam 2000; Salamon 1995; Schmid 2003; Smith and Gronbjerg 2006; Young 2000). Studies on collaboration and cross-sector partnerships have been published extensively in the last few years (Almog-Bar and Schmid 2018; Gazley and Brudney 2007).

This literature provides us with a firm basis for analyzing the relationship between the government and CSOs in general, and in Israel in particular.

\section{The Relationship between the Government and CSOs: Mutuality and Partnership, or Alienation and Mistrust?}

\subsection{Government's Policy toward CSOs}

Political leaders and government administrators sometimes perceive that CSOs which operate on the basis of the values of democracy, equality, freedom of expression, and the right to demonstrate and advocate for disadvantaged and excluded populations, thereby undermine the stability of the government and the resilience of the country. These politicians and administrators perceive CSOs as subverting governmental action, constituting a "deep state" that undermines the authority and power of the government. This, in turn, weakens the perception of 
the legitimacy of the organizations, leading to a reluctance of the government to provide support for the CSOs. Senior officials find themselves keenly aware of the economic crisis but less concerned with its implications for social issues and the growing gap between different strata in society (public interviews with the director general and the director of the budget department in the Ministry of Finance).

This ambivalent attitude is also derived from the administrators' belief that CSOs are inefficient and ineffective. Government officials tend to be reluctant to accept ambiguous and amorphous definitions of goals. They tend to insist upon quantified and measurable outcomes (Hood and Dixon 2015). They expect CSOs to adopt more professional management in general and professional financial and risk management in particular (Brown and Osborne 2013).

In addition, the blurring of the boundaries between nonprofit providers and for-profit organizations raises questions as to the merits and relative advantages of the nonprofit providers (Billis 2016; Schmid 2013). A major change in governmental attitude toward nonprofit organizations involves and increasing preference to forprofit organizations for contracts in many social services (Borowski and Schmid 2000). Such choices on the part of government officials involve the belief that nonprofits have lost their relative advantage over for-profits with regard to efficiency and the provision of quality services.

At the same time, government administrators do not favor the commercialization of nonprofits. On the one hand they expect CSOs to adopt modern management techniques rather than old, obsolete, and inefficient techniques that have not been adapted to current needs. On the other hand, they suspect nonprofits of seeking to accrue profits despite their espoused ideology. One reflection of this attitude was apparent when government administrators accused nonprofit directors of earning high wages as well as criticizing the gaps between their earnings and the wages of their workers (Nonprofit Compensation 2020; The Annual Report of Associations in Israel 2020).

All of these factors have led to fractures in the trust between the government and CSOs, as reflected in the bureaucratic obstacles posed by the government with regard to fulfilling contractual obligations and channeling funds even when they are highly needed during a major crisis by the CSOs.

\subsection{Policy and Organizational Behavior of CSOs in the Covid Crisis}

The contribution of CSOs to the government's ambivalent attitude towards them cannot be ignored. These are related to the behavior of the organizations themselves, their policies, and their strategies of action. 
First, the fact that these organizations remain highly dependent on government funding, which constitutes $41 \%$ of their annual budget (The Annual Report of Associations in Israel 2020), prevents them from expressing opposition to government policy and forces them to conform to regulations in order to ensure the steady flow of resources. Previous studies have shown clearly that when CSOs depend on government funding they "do not bite the hand that feeds them" (Beaton, MacIndoe, and Wang 2020; Chaves, Stevens, and Galaskiewicz 2004; Schmid, Bar, and Nirel 2008). Financial dependence neutralizes protest activity in addition to preventing defiance against the government. For example during the current crisis, attempts to mobilize leaders of the CSOs to take part in protests against the government's policies failed. (Interview with the chair of the umbrella organization of the CSOs, August, 30th 2020).

Also, CSOs are characterized by considerable structural and organizational differentiation and segmentation (Kohm et al. 2000). Half of the organizations in Israel are small, 40\% are medium, and 10\% are large, in terms of annual income (The Annual Report of Nonprofits 2020). High differentiation creates unnecessary duplication and redundancy which in turn leads to waste of resources and inefficiency. Numerous CSOs pursue the same goals: in addition to serving similar populations they offer similar programs even though resources are limited, as is their ability to create a meaningful social impact.

Finally, the poor performance of the organizations' boards does not contribute to strengthening their status vis-à-vis the government (Iecovitz 2002). An examination of the work of the boards of directors revealed that board members were only partially involved in the activities and operations of their organization, and did not attend many board meetings (Banerjee and Seyam 2018). Board members were not involved enough in the efforts of executive directors to position the CSO and to negotiate effectively with the government to change its attitude. During the current crisis, the voices of the board members were hardly heard nor did they support the efforts of the organizations to obtain the government funding needed for their operations and survival (interview with the chair of the umbrella organization of the CSOs on August 30th 2020 and interview with the director general on September 10th 2020). The lack of support from board members, and their absence from the struggle to obtain government support, further weakened the organizations.

\section{Conclusions and Implications for Policy}

The current crisis is just the tip of the iceberg in the relationship between government and civil society organizations, a relationship which has been 
characterized by mistrust and suspicion that pre-dates the outbreak of the pandemic. This crisis has more intensely highlighted the government's position towards CSOs. More puzzling is the question why, precisely during the largest crisis that humanity has experienced in the modern age, the government did not come to the aid of these organizations. Rather governmental agencies and officials dragged their feet, piled up administrative and bureaucratic obstacles, and let organizations fade, crumble, and even die. Government policy and attitude towards CSOs, specifically during times of crisis or national disasters, have received too little theoretical and empirical attention thus far, and constitute a critically important field for further research.

There is no doubt that the CSOs themselves play a part in shaping the alienated behavior of the government towards them. Many of these organizations provide government officials with ample evidence that they are neither efficient nor innovative, and are therefore unlikely to break new ground. Their management is insufficiently professional, and they provide little justification for prioritization over private for-profit organizations. In addition, CSOs have shown little awareness of change in the power-dependency relationship between them and government over the years.

The dysfunctionality of this relationship is both apparent and overwhelming. Not only does it leave the CSO dependent on the Grace of the government as its primary supplier of resources, but government also stands forlorn, dependent upon its alienated organizational partners for their accrued knowledge about their clients, client needs, and what is necessary to meet those needs (Gal and Bar-Nir 2011). This interdependence between the government and the organizations should have been realized, and orchestrated into balance over the years.

The government's disregard for the CSOs' existential needs and unappreciated contributions ultimately harms the citizens of the country, their trust in the government, and in the government itself. CSO leaders have failed to understand this relationship, and have therefore been unable to assume proactive roles in their relationship with governmental agents.

In the new reality created by the coronavirus pandemic, there is no escape from improving cooperation and creating inter-sectoral partnerships between the government and the non-profit organizations in cooperation with the business sector (Almog-Bar and Schmid 2018). Cross-sector partnership based on trust seems an obvious requisite if both partners are to realize their goals and effectively benefit their clients. And, these observations developed in Israel likely apply in many of the world's other nations. Institutional and organizational dysfunctionality would not appear a respecter of national boundaries in a time of global pandemic.

The analysis of the relationship between the government and the organizations has implications for government policy and outlines the strategies it must adopt in order to deal more successfully with crises and pandemics. Government policy makers 
should, in advance, establish policies, guidelines, and procedures for operation during emergency situations. Many governments were caught unprepared to deal with the crisis. Israel's government instruments such as the "National Emergency Authority," have actually been emptied of authority over the years, leaving instead hollow spaces and lacking prepared plans or the ability to deal effectively with the pandemic in real time. Specifically and operatively it is recommended that governments and CSOs should prepare for emergencies and national disasters with a standby "work folder" and have a map for navigating the ship to a safe shore.

Furthermore, in dealing with crisis situations, the government might avoid compartmentalization and exclusion of relevant bodies due to questions of "ego," level of respect, or territorialism, and ensure that knowledge will be shared between relevant bodies in order to better cope with the epidemic. The government might perceive CSOs as important partners in dealing with the crises. These organizations have the ability to provide immediate responses on the ground to populations effected by emergencies - something the government has difficulty doing. The CSOs, on their part, might well choose to become much more entrepreneurial and proactive in their dealings with the government as they utilize their many assets (professional knowledge, client information, treatment plans, programs, human capital, volunteers) which should give them a full place at the table where crisis management his planned and addressed. The government might choose to support CSOs and not ignore their existential needs. After all, a great many of these CSOs serve the purposes of government and stand ready to be "used."

\section{References}

Almog-Bar, M. 2016. "Policy Initiatives towards the Nonprofit Sector: Insights from the Israeli Case." Nonprofit Policy Forum 7 (2): 237-56.

Almog-Bar, M., and H. Schmid. 2018. "Cross-Sector Partnerships in Human Services: Insights and Organizational Dilemmas.” Nonprofit and Voluntary Sector Quarterly 37 (Suppl. 4): $119 \mathrm{~s}-38 \mathrm{~s}$.

Almog-Bar, M., and R. Bar. 2020. Volunteering and Social Involvement During the COVID-19 Crisis in Israel: Information, Insights, and Challenges. Jerusalem, Israel: The Center for the Study of Civil Society and Philanthropy. The Hebrew University of Jerusalem and The Network of Israeli Volunteering. [In Hebrew].

Banerjee, S. K., and A. Seyam. 2018. "Not for Profit Board of Directors and Governance." International Journal of Accounting and Finance Studies 1 (2): 154-72.

Beaton, E., H. MacIndoe, and T. Wang. 2020. "Combining Nonprofit Service and Advocacy: Organizational Structures and Hybridity." Nonprofit and Voluntary Sector Quarterly 23. First published online, September, 23, 2020.

Billis, D. 2016. “Hybrid Associations and Blurred Sector Boundaries.” In The Palgrave Handbook of Volunteering, Civic Participation, and Nonprofit Associations. London: Palgrave MacMillan. 
Borowski, A., and H. Schmid. 2000. "Israel's Long-Term Care Insurance Law after a Decade of Implementation." Journal of Aging \& Social Policy 12: 49-71.

Brown, L., and S. P. Osborne. 2013. "Risk and Innovation, towards a Framework for Risk Governance in Public Services.” Public Management Review 15: 186-208.

Chaves, M., S. L. Stephens, and J. Galaskiewicz. 2004. "Does Government Funding Suppress Nonprofits' Political Activity?” American Sociological Review 69: 292-316.

Gal, J., and D. Bar- Nir. 2011. "Who has the Power? the Role of NPOs in Local Authorities." Voluntas 22: $1-25$.

Gazley, B., and J. L. Brudney. 2007. "The Purpose (and Perils) of Government-Nonprofit Partnership." Nonprofit and Voluntary Sector Quarterly 36: 389-415.

Gronbjerg, K. A., and L. M. Salamon. 2012. "Devolution, Privatization, and the Changing Shape of Government-Nonprofit Relations." In The State of Nonprofit America, 2nd ed., edited by Salamon, L. M., 549-86. Washington, D.C.: Brookings Institution Press.

Hood, C., and R. Dixon. 2015. A Government that Worked Better and Cost Less? Evaluating Three Decades of Reform and Change in the UK Central Government. Oxford, UK: Oxford University Press.

lecovitz, E. 2002. Public Boards of Third Sector Organizations in Israel: Structural, Functional and Organizational Characteristics and Perspectives. Beersheba, Israel: Israeli Center for Third Sector Research, Ben Gurion University of the Negev. [In Hebrew].

Katz, H., and G. Feit. 2020. Individual Giving and Volunteering in Israel During the COVID-19 Crisis: The Second Wave, Part 2. Tel Aviv, Israel: The Institute for Law and Philanthropy, The Buchmann Faculty of Law, Tel Aviv University.

Kohm, A., D. La Piana, A. Vergara-Lobo, and H. Gowdy. 2000. Strategic Restructuring: Findings from a Study of Integrations and Alliances Among Nonprofit Social Service and Cultural Organizations in the United States. Chicago: University of Chicago, Chapin Hall Center for Children and Strategic Solutions.

Najam, A. 2000. "The Four-C's of Third Sector-Government Relations, Cooperation, Confrontation, Complementarity, and Co-optation." Nonprofit Management and Leadership 10: 375-95.

Nonprofit Compensation Report. 2020. Guidestar, 20th ed. Tel Aviv: Candid. [In Hebrew].

Salamon, L. M. 1995. Partners in Public Service: Government and the Nonprofit Sector in the American Welfare State. Baltimore, MD: Johns Hopkins University Press.

Schmid, H. 2003. "Rethinking the Policy of Contracting Out Social Services to Non-governmental Organizations: Lessons and Dilemmas.” Public Management Review 5 (3): 307-23.

Schmid, H. 2013. "Nonprofit Human Services: Between Identity Blurring and Adaptation to Changing Environments." Administration in Social Work 37 (3): 242-56.

Schmid, H., M. Bar, and R. Nirel. 2008. "Advocacy Roles of Nonprofit Human Service Organizations: Implications for Policy.” Nonprofit and Voluntary Sector Quarterly 37 (4): 581-600.

Smith, S. R., and K. A. Gronbjerg. 2006. "Scope and Theory of Government-Nonprofit Relations." In The Nonprofit Sector: The Research Handbook, edited by Powell, W. W., and Steinberg, R., 432-46. New Haven, CT: Yale University Press.

The Annual Report of Associations in Israel. 2020. Ministry of Justice. Tel Aviv: The Registrar of Associations and The Institute for Law and Philanthropy, The Buchmann Faculty of Law, Tel Aviv University. [in Hebrew].

The Influence of Covid -19 on Civil Society Organizations. 2020. Civil Leadership. Tel Aviv.

Young, D. R. 2000. "Alternative Models of Government-Nonprofit Sector Relations: Theoretical and International Perspectives." Nonprofit and Voluntary Sector Quarterly 29: 149-72. 